\title{
A right to die
}

\author{
Alison L McAdams
}

The existence and extent of a right to die was recently examined by the Court of Appeal in the case of $\operatorname{Re~J~(a~}$ minor). ${ }^{.}$The case adds to the judicial guidance available when decisions have to be taken regarding treatment of severely disabled patients or those who are facing inevitable death. Not all such cases have to be referred to the courts, only those in which the patient is a ward of court. Nevertheless, the debate concerning a right to die in $\operatorname{Re} \mathrm{J}$ is of great concern to all those caring for patients who have suffered severe and irreversible physical and mental handicaps but who continue to live. Courts, parents, social services, doctors, and medical staff have found themselves embroiled in controversies over aspects of the care of such patients. Some guidance at least is now available.

\section{The case}

Baby J was said to suffer from "almost every conceivable misfortune." Born very prematurely, he was not breathing at birth and had to be placed on a ventilator almost immediately. After several months he was able to breathe independently but soon collapsed and had to be resuscitated and ventilated a second time. Even when breathing independently, $J$ was severely and permanently brain damaged. He seemed to be blind and deaf and was unlikely ever to be able to speak or develop even a limited intellectual capacity. Medical evidence indicated that he was likely to develop serious spastic quadriplegia. He was, however, likely to experience pain to the same extent as any normal baby. Even on the most generous estimate, J's life expectancy was reduced at most to his late teens, but it was generally expected that he would die much earlier.

The decision in the case of $\mathrm{J}$ was whether to reventilate him if he stopped breathing again. This was a painful procedure and was unlikely to be successful a third time. However, while J breathed normally he was neither dying nor on the point of death.

\section{Similar judgments}

The case of baby $\mathrm{J}$ was distinct from the two other recent cases concerning treatment of newborn infants. In the case of $\operatorname{Re} C(a \text { minor })^{2}$ the child was terminally ill, and it was held that medical opinion was to be respected if it was decided that treatment should be aimed at easing suffering rather than prolonging life for a short time. This decision was taken against the background of the "sad but fundamental truth that $\mathrm{C}$ was dying and the only question was how soon this would happen." If a child, regardless of great disablement, had the chance of a normal life span, albeit within the bounds of that disability, then the decision in the case of $\operatorname{Re} B$ (a minor) ${ }^{3}$ laid down that medical treatment had to allow for that chance. A child with Down's syndrome had developed an intestinal blockage that would prove fatal unless operated on, but otherwise he could have a life expectancy of 20 to 30 years. Looking at the child's best interests, it was not for the court to say that such a life ought to be ended. The case of Baby $\mathrm{J}$ was more complex than these.

\section{Decision on baby $\mathbf{J}$}

Initially Mr Justice Scott Baker held that it would not be in J's best interests to reventilate him if he stopped breathing "unless to do so seems appropriate to the doctors caring for him given the prevailing clinical situation." He recommended, however, that other aspects of standard treatment should continue. The official solicitor appealed against this decision on behalf of the child.

In the Court of Appeal Lord Donaldson first sought to define the relationship between the court, the doctors, the child, and his parents. He said that doctors owed a child a duty to care in accordance with good medical practice-namely, that recognised as appropriate by a competent body of professional opinion. If serious invasive treatment was required doctors were duty bound to obtain the consent of the parents when time permitted. Parents owed their children a duty to act in their child's best interests and had to give or withhold consent in the light of this. If a court had assumed the rights and duties of parents then the decision whether to give consent belonged to that court.

\section{FIRST SUBMISSION}

Against this background the official solicitor appealed on two grounds. Firstly, he contended that if a child was terminally ill, as in the case of $\operatorname{Re} C$, a court was never justified in approving the withholding of life saving treatment, regardless of the quality of life that the child would subsequently experience. Lord Donaldson stated that neither the courts nor parents had a right to impose death but they did have a right to decide on treatment that would not avert death. Lord Justice Balcombe said that the only test was that the interest of the ward be paramount, and that there should be no absolute rule, as "to preserve life at all costs, whatever the quality of the life to be preserved, and however distressing to the ward may be the nature of the treatment necessary to preserve life, may not be in the interests of the ward." The third member of the court, Lord Justice Taylor, added that as long as there was no question of deliberately ending or shortening the life of the child "the court is entitled in the best interests of the child to say that deliberate steps should not be taken artificially to prolong its miserable life span."

\section{SECOND SUBMISSION}

The second submission by the official solicitor was that withholding consent to such life saving treatment was justified only if it was certain that the quality of the child's subsequent life would be "intolerable to the child," "bound to be full of pain and suffering," and "demonstrably so awful that in effect the child must be condemned to die."

Lord Donaldson endorsed the use of a balancing exercise in assessing the course that was in the best interests of the child. What the doctors and the court had to decide was whether, in the child's best interests, a particular medical treatment should be used which, as a side effect, would render death more or less likely. What was never justified was bringing about the child's
Alison L McAdams, LLM, solicitor

$B M \mathcal{1}$ 1992;304:765-6 
death as the primary purpose. Again, by distinguishing between the right to kill and the right to die he concluded that the official solicitor's appeal should be dismissed. Lord Justice Balcombe warned against setting down "an all embracing test since the circumstances of these tragic cases are so infinitely various." Similarly, Lord Justice Taylor thought that the proper criterion must be a matter of degree and that all the circumstances should be looked at to decide if "such a life would be so afflicted as to be intolerable to that child."

\section{Implications}

It was decided that the court could direct that treatment need not be given in this particular case, even though death would naturally ensue. In reaching this decision, the court has accepted that it can be wrong to prolong life at any cost. The seemingly limitless bounds of medical technology need not be employed "officiously to keep alive" a patient without considering his or her best interests. However, a strong safeguard came in the statement that "what can never be justified is the use of drugs or surgical procedures with the primary purpose of hastening the moment of death." It is important to draw a line between that area on which the court has made a decision and the area which was felt to be clearly outside the boundaries of the debate - as Lord Donaldson explained, "What is at issue in these cases is not a right to impose death, but a right to choose a course of action which will fail to avert death."

1 Re f (a minor) [1990] 3 All ER 930

$2 \operatorname{ReC}$ (a minor) [1989] 2 All ER 782

3 Re $B$ (a minor) [1990] 1 All ER 927

Lesson of the Week

\title{
Fatal outcome with use of rectal morphine for postoperative pain control in an infant
}

\author{
G K Gourlay, R A Boas
}

Safe use of opioids demands dosage

adjustments based on monitoring of pain relief, sedation, and respiratory depression
Pain Management Unit, Flinders Medical Centre, Bedford Park, South Australia 5042, Australia G K Gourlay, PHD, chief hospital scientist

Section of Anaesthetics, Department of

Pharmacology and Clinical Pharmacology, School of Medicine, University of

Auckland, Auckland, New Zealand

R A Boas, fFaRaCs, professor

Correspondence to:

Dr Gourlay.

BMF 1992;304:766-7
Increasing emphasis on better treatment of postoperative pain has led to innovative techniques for administering drugs and the development of acute pain management teams in many countries. Such programmes should recognise the narrow therapeutic ratio for opioid drugs and include staff education and clinical protocols to enhance both efficacy and safety of care. We report a fatal outcome with rectal morphine in an infant after nephrectomy, drawing attention to these needs.

\section{Case report}

A $71 / 2$ month old boy weighing $9 \mathrm{~kg}$ with refractory hypertension from neonatal renal vein thrombosis was admitted to a large regional hospital in New Zealand for a left nephrectomy. Anaesthetic management (balanced relaxant technique) proceeded uneventfully, with blood loss estimated to be $10 \mathrm{ml}$. The child breathed promptly after reversal of anaesthesia and showed stable blood pressure, pulse, and respiratory rate throughout the stay in the recovery room.

Orders for postoperative analgesia were discussed by the consultant surgeon and anaesthetists during the operation and were for $1.5 \mathrm{mg}$ of morphine intramuscularly, two to three hourly as required. However, after the ward nursing staff expressed humanitarian concern about repeated intramuscular injections the ward house staff changed the order to morphine suppositories ( $4 \mathrm{mg}$ ) four hourly as needed for pain. There were no specific orders covering the frequency of recording or limits for assessment of respiratory status or extent of pain relief. The first suppository was given six hours after reversal of anaesthesia and the intervals between successive suppositories were 4.5 , $3.75,4.75$, and 3.75 hours. The child's condition was essentially unremarkable for the first 22 hours, and he passed urine twice during this period.

The child's pulse rate changed appreciably 22 hours after operation, rising from 120 to 168 beats $/ \mathrm{min}$. About this time the infant was reviewed by the consultant surgeon, his registrar, and the senior nursing staff of the ward. The surgeon noted that the patient was sedated, a little cyanotic in the periphery, and cold, with a sluggish return of circulation after digital compression. Only at the end of this examination was the surgeon informed that his patient was receiving morphine rectally rather than intramuscularly, but no new orders were given except to cover the child. Three hours after the fifth morphine suppository was given (about 30 minutes after the examination) the infant suffered a cardiac arrest with profound cyanosis, from which he was resuscitated.

The serum morphine concentration (assay specific for unconjugated morphine) in a sample collected 1.5 hours after the cardiac arrest was $0.094 \mathrm{mg} / \mathrm{l}$. Despite vigorous intensive care, the infant deteriorated without regaining consciousness and died the next day. A postmortem examination noted the cause of death as cerebral hypoxia, with no evidence of surgical or cerebral haemorrhage or any pneumonic consolidation

Hospital records indicated that there had been little formal assessment of the efficacy of the rectal morphine or of any possible relation between the dose or frequency and adverse effects such as sedation and respiratory depression. There were only general comments such as "with effect," which presumably related to analgesia, though physiological measures of blood pressure, pulse, respirations, and each new rectal dose were clearly noted. When questioned after the event many of the nurses responded that, although the patient was comfortable, the next morphine suppository was inserted because it was due. An appropriate assessment would probably have indicated that the last two doses were not needed.

\section{Discussion}

This case exemplifies several principles of management that may well apply to other novel routes of giving drugs to both adult and paediatric patients.

The first important factor relates to the pharmacology of rectal morphine, particularly the large variability of absorption. Various reports suggest that the oral bioavailability of morphine varies between $10 \%$ and $50 \%$ with a mean value of about $30 \% .^{12}$ Therefore, in 